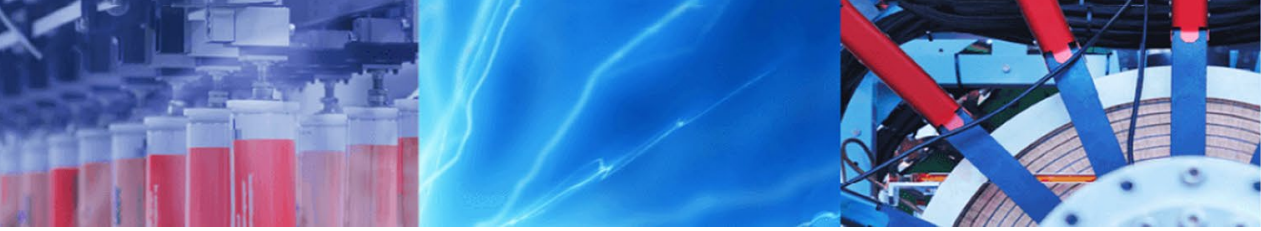

Research Article

\title{
Pseudomorphic transformation and post synthetic modification of amorphous silica for $\mathrm{CO}_{2}$ sorption applications
}

\author{
David G. Madden ${ }^{1}$ (D Emma A. Daniels ${ }^{1} \cdot$ John P. Hanrahan ${ }^{2} \cdot$ Joseph Tobin $^{2} \cdot$ Teresa Curtin $^{1}$
}

(c) Springer Nature Switzerland AG 2019

\begin{abstract}
Template directed porous silica has shown significant promise in numerous applications such as gas sorption, catalysis and pharmaceutical drug delivery. Mesoporous silicas such as MCM-41, SBA-15 and KIT-6 have been widely reported; however, thus far these materials require long synthesis processes and expensive starting materials. As an alternative, pseudomorphic transformations can convert low-grade amorphous silica into more useful materials. Herein, we demonstrate the effect of pseudomorphic transformations upon the properties of non-porous silica spheres. Surface area can be increased from $<2 \mathrm{~m}^{2} \mathrm{~g}^{-1}$, for non-porous silica spheres, to $724 \mathrm{~m}^{2} \mathrm{~g}^{-1}$ for the resulting pseudomorphic species. Silica species were subsequently functionalised with aminopropyltriethoxysilane (APTES) and tetraethylenepentamine (TEPA) via post-synthetic modification. Post-synthetic modification was found to significantly enhance the $\mathrm{CO}_{2}$ sorption performance of the silica species with $\mathrm{CO}_{2}$ sorption capacities of up to ca. $92 \mathrm{mg} \mathrm{CO} \mathrm{g} \mathrm{g}^{-1}$ achieved, compared to a maximum uptake of $18 \mathrm{mg} \mathrm{CO}_{2} \mathrm{~g}^{-1}$ for the non-porous silica variants.
\end{abstract}

Keywords Mesoporous silica $\cdot \mathrm{CO}_{2}$ adsorption · Gas separation

\section{Introduction}

Carbon dioxide $\left(\mathrm{CO}_{2}\right)$ is one of the major global contributors to global warming. $\mathrm{CO}_{2}$ emissions from manmade sources have come under scrutiny as a driver of climate change. The ambient concentration of $\mathrm{CO}_{2}$ has increased from about $280 \mathrm{ppm}$ to the current levels of over $400 \mathrm{ppm}$ since the beginning of the industrial revolution $[1,2]$. Combustion of fossil fuels and related practices are the primary sources of such emissions. The development of suitable carbon capture and sequestration technologies is a solution to tackle global warming. Conventional $\mathrm{CO}_{2}$ capture is currently performed using energy intensive liquid amine absorption [3]. As an alternative to the conventional technologies, adsorption using porous materials has shown significant potential in this context. Physisorbents such as metal-organic materials (MOMs) [4-6], activated carbons $[7,8]$ and zeolites $[7,9,10]$ have been studied; however, thus far no suitable physisorbents are available due to issues with water competition and stability $[9,11,12]$.

Chemisorbents have also shown significant potential in the context of $\mathrm{CO}_{2}$ sorption. A large amount of work has been carried out using amine modified mesoporous silica's such as MCM-41 [13-20], MCM-48 [19, 21, 22], SBA-15 $[19,23-31]$ and SBA-16 [19, 32, 33]. These materials have shown significant promise for multiple applications in gas sorption, catalysis [34] and pharmaceutical drug delivery [35]. While these mesoporous silicas have exhibited excellent performance, they can often require complex synthesis procedures and/or expensive starting materials. As an

Electronic supplementary material The online version of this article (https://doi.org/10.1007/s42452-019-1040-0) contains supplementary material, which is available to authorized users.

David G. Madden, davidgerardmadden@gmail.com; $\bowtie$ Teresa Curtin, teresa.curtin@ul.ie | ${ }^{1}$ Department of Chemical Sciences, Bernal Institute, University of Limerick, Limerick, Republic of Ireland. ${ }^{2}$ Glantreo Ltd, Environmental Research Institute (ERI), Lee Road, Cork, Republic of Ireland.

SN Applied Sciences (2019) 1:996| https://doi.org/10.1007/s42452-019-1040-0

Received: 21 June 2019 / Accepted: 1 August 2019 / Published online: 7 August 2019 
alternative, Stein et al. examined modification of Stöber particles [36] and Zeolites [37] using a desilication and reassembly process known as pseudomorphic transformation to tailor the properties and morphologies of silicates and aluminosilicates for a number of analytical and catalytic applications. Pseudomorphic transformations has been applied in a number of previous studies for synthesis of novel materials for chromatography type applications $[38,39]$, however, this process can also be applied to low grade/waste silica with low surface area and pore volume, such as spent catalysts, in order to utilise cheaper silica sources for new applications.

In this contribution, we investigate the effect of pseudomorphic transformations of non-porous materials (Stöber particles) upon the properties of the resulting silica materials. Stöber particles were chosen as the starting material due to their ultra-low surface area. These materials were subsequently functionalised with amine moieties in order to examine the effect of pseudomorphic transformations upon their $\mathrm{CO}_{2}$ sorption performance. The performance and characterisation of these materials was evaluated from the following experiments: single component sorption studies; FTIR; dynamic gas mixture breakthrough experiments; and gravimetric gas uptake experiments.

\section{Experimental}

\subsection{Adsorbent synthesis}

Non-porous silica spheres were prepared using previously reported methods [40-42]. Silicon dioxide particles were obtained using the modified Stöber method by TEOS hydrolysis in alcohol-water solution in the presence of ammonia hydroxide (50 vol\% ethanol; $1.0 \mathrm{M}$ ammonia). $1.4 \mu \mathrm{m}$ in diameter particles were obtained by multistage growth to specified sizes using particles obtained at the previous synthesis stage as seeds for further growth. Spherical silica particles were mixed in an appropriate volume of alcohol-water-ammonium mixture of the same composition and new portions of TEOS were added. The added amount of TEOS ensured an increase of particle diameter. Stöber particles were dried at room temperature before being calcined at $600^{\circ} \mathrm{C}$. This synthesis method was used to prepare non-porous spheres between 0.4 and $4.5 \mu \mathrm{m}$ in diameter. Scanning electron microscopy was used to verify particle diameters. Stöber silica particles were used in this study due to their extremely low surface area and lack of porous networks.

Pseudomorphic transformation were then carried out based on the method previously described by Yoo et al. [36]. Stöber particles were subjected to a silica destruction-reassembly process. In a typical pseudomorphic treatment $0.18 \mathrm{~g}$ of silica was mixed with $10 \mathrm{ml}$ ethanol, $40 \mathrm{ml}$ deionised $\mathrm{H}_{2} \mathrm{O}, 0.05 \mathrm{~g} \mathrm{NaOH}$ and between 0.05 and $0.3 \mathrm{~g} \mathrm{CTAB}$. These were stirred at $40{ }^{\circ} \mathrm{C}$ for $0.5 \mathrm{~h}$ before being transferred to a Teflon-lined autoclave at which point hydrothermal reactions were carried out at $100^{\circ} \mathrm{C}$ for $24 \mathrm{~h}$. The resultant mixture was then filtered and washed with copious amounts of water, left dry at room temperature for $24 \mathrm{~h}$ before being calcined at in air $550^{\circ} \mathrm{C}$ for $10 \mathrm{~h}$ to ensure complete template removal.

Post-synthetic modification was carried out using impregnation and grafting methods. In a typical grafting, aminopropyltriethoxysilane (APTES) was added drop wise to an appropriate amount of porous silica spheres until the solid was saturated with amine. The sample was heated to $100{ }^{\circ} \mathrm{C}$ under vacuum overnight. In a typical impregnation process, $1 \mathrm{~g}$ of silica was refluxed with a desired amount of tetraethylenepentamine (TEPA) and $15 \mathrm{ml}$ of ethanol. A ca. $40 \mathrm{wt} \%$ loading was used for both grafting and impregnation techniques. After $3 \mathrm{~h}$ reflux, the amine solution was filtered and the resulting solid was heated to $80^{\circ} \mathrm{C}$ under vacuum overnight to remove excess solvent. APTES and TEPA were chosen in this study as these are amongst the most commonly reported amines for $\mathrm{CO}_{2}$ sorption applications.

\subsection{Characterisation}

Thermogravimetric analysis was carried out under nitrogen using a TGA instrument TA Q50. Experiments were carried out using platinum pans and with a gas flow rate of $60 \mathrm{~mL} \mathrm{~min}{ }^{-1}$. The data was collected in the High Resolution Dynamic mode with a temperature ramp rate of $20^{\circ} \mathrm{C} \mathrm{min}^{-1}$ up to $750^{\circ} \mathrm{C}$. The IR spectra of the synthesized materials were recorded using a Perkin Elmer Spectrum 100 ATR-FTIR. The samples were analyzed in the wavelength region $750-4000 \mathrm{~cm}^{-1}$. Scanning electron microscopy (SEM) analysis of the adsorbents was conducted on a Hitachi SU-70 SEM. The powder samples were placed on carbon tape and then adhered to aluminium stubs before being placed into the SEM chamber. The surface areas of the micro-/mesoporous silica materials were measured using $\mathrm{N}_{2}$ adsorption/desorption isotherms at $77 \mathrm{~K}$ on a Quantachrome Autosorb-1 volumetric analyser. Each sample was degassed for $20 \mathrm{~h}$ at $25^{\circ} \mathrm{C}$ prior to a measurement. Surface areas of synthesised materials were determined using the Brunauer, Emmett and Teller (BET) technique. Average pore size and volumes were determined from a 40-point BET surface area plot, with measurements taken in the $0.1-0.3 P / P_{0}$ range. 


\section{$2.3 \mathrm{CO}_{2}$ adsorption studies}

$\mathrm{CO}_{2}$ uptake measurements were performed using a TGA instrument TA Q50. Samples were initially heated to $80^{\circ} \mathrm{C}$ to remove atmospheric impurities. Upon cooling to $25^{\circ} \mathrm{C}$, samples were exposed to a $15 \% \mathrm{CO}_{2} / 85 \% \mathrm{~N}_{2}$ gas mixture. Weight changes versus time was constantly recorded. $\mathrm{CO}_{2}$ breakthrough measurements and temperature-programmed desorption (TPD) were carried out using a fixed-bed flow system shown in Fig. S1 in the supporting information. $100 \mathrm{mg}$ of sorbent was placed in a quartz reactor (length $400 \mathrm{~mm}$, internal diameter $6 \mathrm{~mm}$ ). The sample was held in the reactor using quartz wool. Helium (99.999\%, BOC Gases), at $44 \mathrm{~cm}^{3} \mathrm{~min}^{-1}$, was then passed through the reactor at room temperature until a constant signal was observed using mass spectrometry (MS). The temperature was increased at a rate of $10^{\circ} \mathrm{C} \mathrm{min}-1$ to $100^{\circ} \mathrm{C}$ to remove $\mathrm{H}_{2} \mathrm{O}$ and any volatiles on the sample. Upon cooling to $25^{\circ} \mathrm{C}, 15 \% \mathrm{CO}_{2} / 85 \% \mathrm{~N}_{2}$ gas was then introduced to the sorbent sample. Upon complete breakthrough of $\mathrm{CO}_{2}$, as indicated by $\mathrm{MS}$, the $15 \% \mathrm{CO}_{2} / 85 \% \mathrm{~N}_{2}$ mix was left flow over sample for a further 10 min to ensure full $\mathrm{CO}_{2}$ saturation, at this point the $\mathrm{CO}_{2}$ flow was switched off. The $\mathrm{CO}_{2}$ level was then allowed to return to background concentrations before the sample was heated to $100^{\circ} \mathrm{C}$ at a rate of $10^{\circ} \mathrm{C} \mathrm{min}^{-1}$ in helium flow. The gas composition leaving the reactor was continuously monitored by the MS. For multiple cycle $\mathrm{CO}_{2}$ breakthrough studies, a regeneration temperature of $60^{\circ} \mathrm{C}$ was used to prevent sample degradation.

\section{Results}

Different sorbents were prepared in the study using a variety of synthesis techniques. The sample nomenclature used to identify the sorbents includes the amount of amine in the synthesis solution relative to the solid, the solid used, the preparation technique and the solvent used (where appropriate). For example, 40\% APTES-PSU1-G describes a solid prepared using the amine APTES, with a $40 \mathrm{wt} \%$ loading, pseudomorphic-1 (PSU-1), "G" represents the preparation technique, in this case reflux/ grafting. Sorbents prepared by impregnation are represented by the symbol "I". The symbols " $0.4 \mu \mathrm{m} \mathrm{SFB"} \mathrm{is}$ used to represent a $0.4 \mu \mathrm{m}$ in diameter, Stöber particle. Table 1 lists the set of solid supports synthesised using pseudomorphic treatments including the amount of CTAB used during the synthesis step and the physicochemical properties such as surface area, pore size and pore volume.
Table 1 Physicochemical properties of synthesised solids

\begin{tabular}{llcll}
\hline Sample & CTAB $(\mathrm{g})$ & $\mathrm{S}_{\mathrm{BET}}\left(\mathrm{m}^{2} \mathrm{~g}^{-1}\right)$ & $\begin{array}{l}\text { Pore } \\
\text { volume } \\
\left(\mathrm{cm}^{3} \mathrm{~g}^{-1}\right)\end{array}$ & $\begin{array}{l}\text { Pore } \\
\text { diameter } \\
(\mathrm{nm})\end{array}$ \\
\hline SFB & - & $<2$ & $<0.001$ & - \\
PSU-1 & 0.05 & 25 & 0.023 & 3.6 \\
PSU-2 & 0.10 & 315 & 0.155 & 2.8 \\
PSU-3 & 0.15 & 577 & 0.316 & 2.8 \\
PSU-4 & 0.20 & 724 & 0.402 & 2.9 \\
PSU-5 & 0.25 & 557 & 0.234 & 2.7 \\
PSU-6 & 0.30 & 322 & 0.206 & 2.9 \\
PSU-7 & 0.35 & 36 & 0.015 & 2.8 \\
40\% APTES-PSU- & - & 12 & - & - \\
$4-G$ & & & & - \\
$40 \%$ TEPA-PSU-4-I & - & 42 & - & - \\
\hline
\end{tabular}

\subsection{Characterisation of synthesised materials}

The structural morphology of synthesised solids was examined using SEM microscopy. Figure 1a shows an SEM image for monodispersed $1.4 \mu \mathrm{m}$ diameter Stöber silica spheres (SFB). Figure $1 \mathrm{~b}$ shows the change in morphology of the Stöber particles when pseudomorphic treatment is carried out. The Stöber particles lose their monodispersivity and merge to form a new solid (PSU-4). Figure 1c shows a section of pseudomorphic silica which contains post pseudo treatment spheres which split during hydrothermal treatment. Figure 1d shows the resultant silica (PSU-7) when high concentrations of CTAB are used during pseudo treatment.

To investigate the physicochemical properties of the synthesised silica species, $\mathrm{N}_{2}$ adsorption/desorption testing was performed at $77 \mathrm{~K}$ (Fig. 2 and Figs. S2-S9). The results of surface area analysis, pore volume and average pore size distributions are presented in Table 1. Figure $2 \mathrm{a}$ illustrates the changes in the $\mathrm{N}_{2}$ adsorption/desorption behaviour upon pseudomorphic transformation of non-porous silica spheres into the resulting porous silica species. The $\mathrm{N}_{2}$ uptake for the SFB spheres was found to be negligible and equated to $<2 \mathrm{~m}^{2} \mathrm{~g}^{-1}$ surface area. In contrast, the surface area of the pseudomorphic materials ranged from $25 \mathrm{~m}^{2} \mathrm{~g}^{-1}$, for PSU-1, to $724 \mathrm{~m}^{2} \mathrm{~g}^{-1}$ for PSU-4. The high surface of PSU-4 is comparable to those of previously reported pseudomorphic materials $[36,38$, 39]. This dramatic change was also reflected in the increase in pore size (ca. $0.3 \mathrm{~nm}$ ) and pore volume (ca. $0.4 \mathrm{~cm}^{3} \mathrm{~g}^{-1}$ ) compared to the non-porous SFB materials (Table 1, Fig. $2 \mathrm{~b}$ and Figs. S2-S9). Wall thickness of PSU-4 was found to be indeterminable due to the absence of a (100) reflection during small angle X-rays scattering (SAXS) (Fig. S11). The lack of a (100) reflection can be attributed to the presence of individual mesopores with less long-range order and 
Fig. 1 SEM images of a $1.4 \mu \mathrm{m}$ Stöber silica spheres (SFB), $\mathbf{b}$, c resulting silica species after pseudomorphic transformations (PSU-4) and $\mathbf{d}$ destructive impact on silica formation of excessive CTAB use during pseudomorphic transformations (PSU-7)
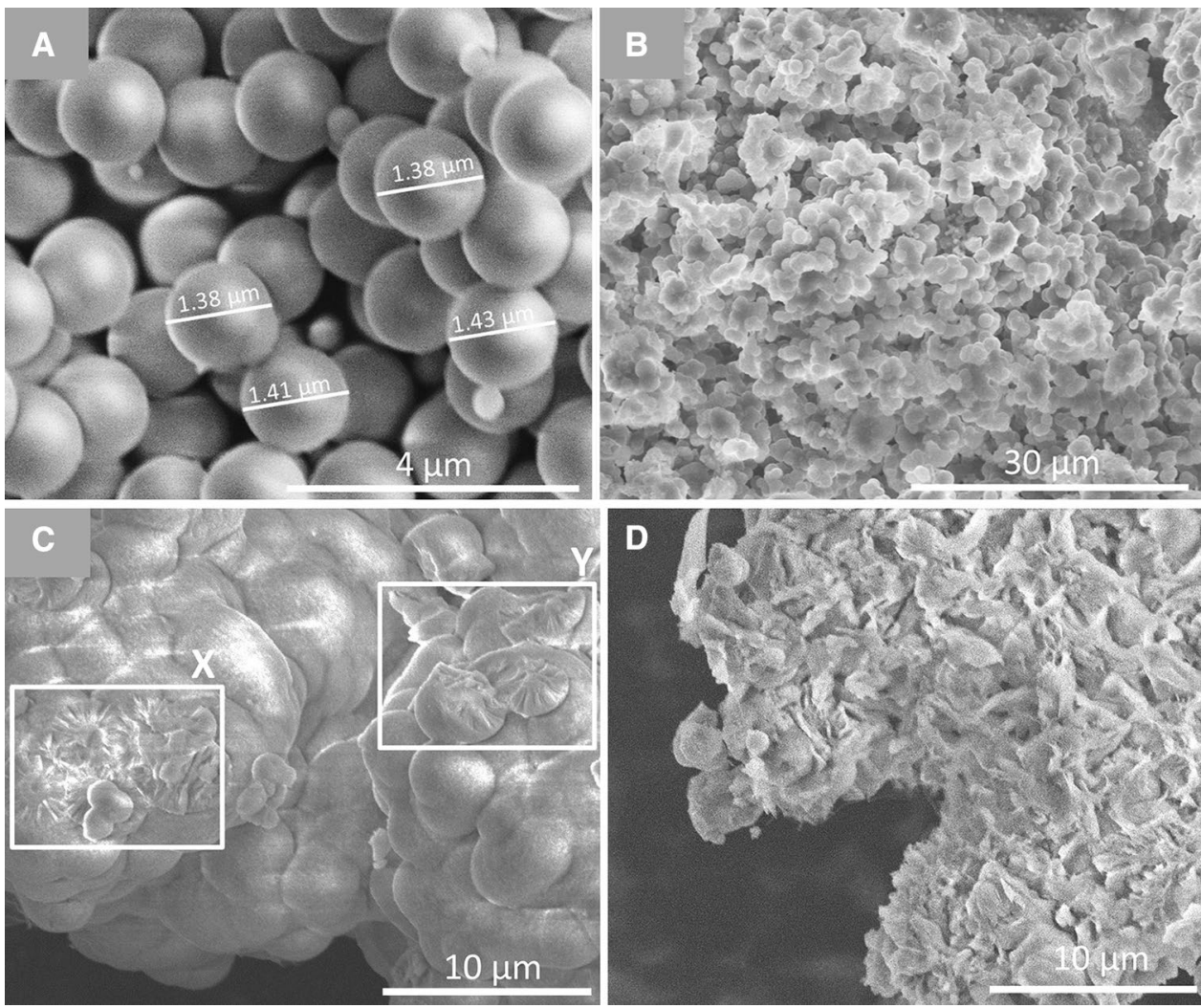

an overall spherically symmetric pore distribution [36]. The increase in the amount of CTAB used during pseudomorphic transformations was found to significantly impact the physicochemical properties of the resulting materials (Table 1, Fig. 2c). Excessive CTAB was found to negatively impact the formation of pseudomorphic materials. $\mathrm{N}_{2}$ adsorption/desorption studies were also performed on amine functionalised materials (Table 1, Fig. $2 \mathrm{~d})$. The reduction in terms of surface area and porosity $\left(<50 \mathrm{~m}^{2} \mathrm{~g}^{-1}\right.$ surface area, negligible pore volume) can be attributed to pore blocking as a result of the introduction of functional amino groups.

To evaluate the effect of post-synthetic modification, thermogravimetric analysis (TGA) experiments were carried out on the amino functionalised materials. Figure $2 \mathrm{e}$ shows the TGA profiles for both modified and unmodified PSU-4. The TGA profile for PSU-4 unmodified silica exhibits a total weight loss of ca. $4 \%$. This weight loss occurs $<200{ }^{\circ} \mathrm{C}$ and can be attributed to removal of adsorbed atmospheric species $\left(\mathrm{CO}_{2}, \mathrm{H}_{2} \mathrm{O}\right.$ etc.) from the silica surface. The modified solids typically contain three distinct regions. An initial weight loss occurs below $200^{\circ} \mathrm{C}$, this once again can be attributed to the removal of adsorbed atmospheric species. As the temperature increases beyond $200^{\circ} \mathrm{C}$ the next significant weight loss can be attributed to decomposition of organic materials present in the solid after synthesis including amine and solvents. The third region occurs at temperatures in excess of $700^{\circ} \mathrm{C}$ at which point the weight loss plateaus indicating that silica accounts for the remaining weight. The $40 \%$ APTES-PSU-4-G solid shows an overall weight loss of just under $14 \%$ at $700{ }^{\circ} \mathrm{C}$ while the $40 \%$ TEPA-PSU-4-I sample shows an overall weight loss of $39 \%$. These weight losses correspond to amine contents of ca. 2.41 and $10.30 \mathrm{mmol} \mathrm{N} \mathrm{g}^{-1}$ for $40 \%$ APTES-PSU-4-G and 40\% TEPA-PSU-4-I, respectively.

In order to further evaluate the effect of post-synthetic modification, FTIR studies were carried out on the amino functionalised materials. Figure $2 \mathrm{f}$ show the FTIR spectra of APTES and TEPA modified PSU-4 samples compared to the purely siliceous PSU-4 material. The bands at about $1080 \mathrm{~cm}^{-1}$ refer to asymmetric and symmetric Si-O-Si stretches which dominate the spectra of all samples. The main differences from sample to sample between the spectra were due to bands attributed to $\mathrm{C}-\mathrm{H}$ stretches, clearly identified at 2937 and $2875 \mathrm{~cm}^{-1}$, and weak bands due to $\mathrm{N}-\mathrm{H}$ stretches at $1590 \mathrm{~cm}^{-1}$, associated to the presence of the aminopropyl group. $\mathrm{N}-\mathrm{H}$ vibrations at $1590 \mathrm{~cm}^{-1}$ can also be associated with the $\mathrm{NH}_{3}$ deformation of the protonated primary amine group [43,44].

\section{2 $\mathrm{CO}_{2}$ adsorption studies}

Temperature programmed desorption (TPD) studies were carried out to evaluate the $\mathrm{CO}_{2}$ sorption capacities of the 

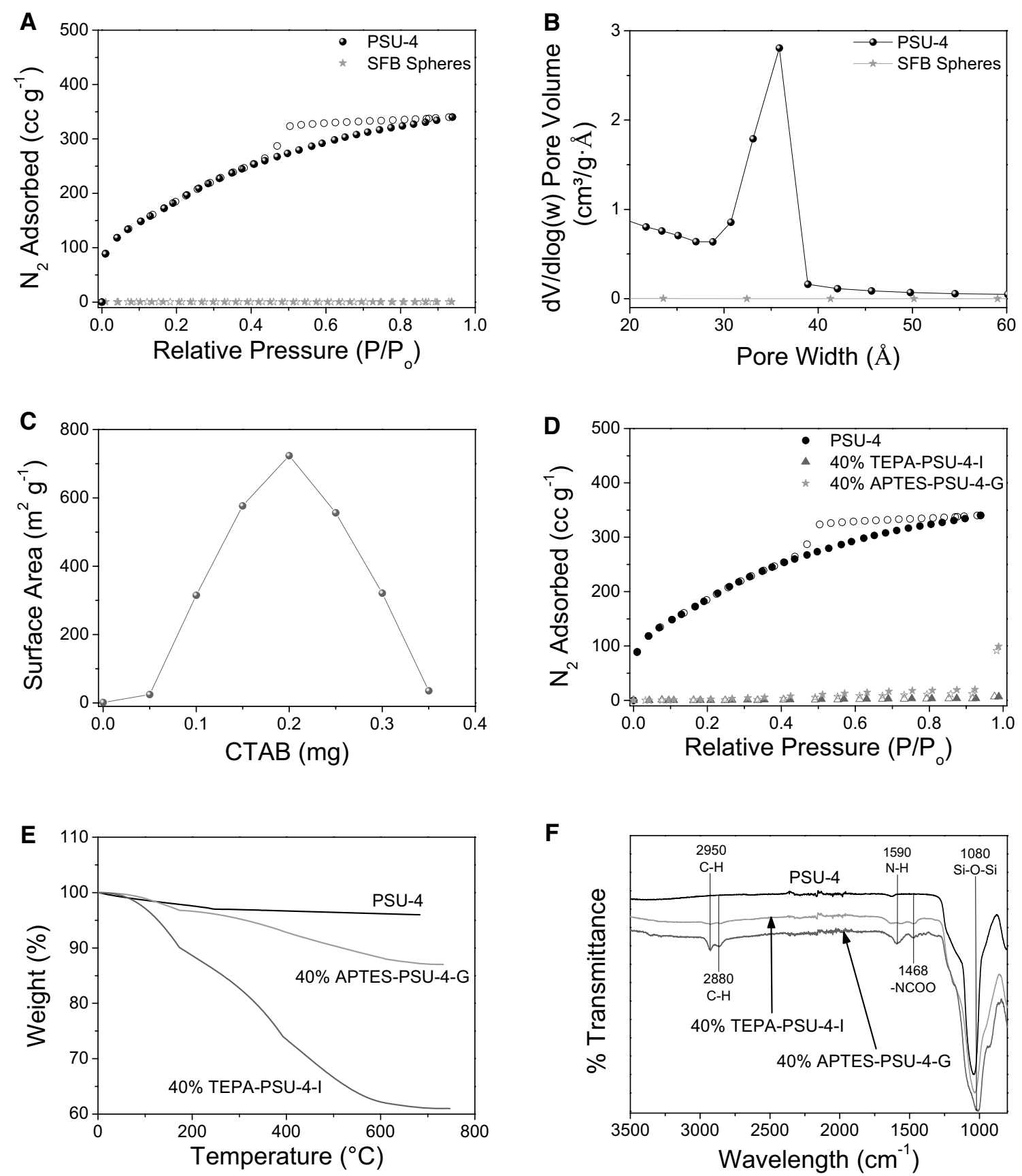

Fig. 2 a $\mathrm{N}_{2}$ adsorption/desorption isotherms and $\mathbf{b}$ pores size distributions for SFB spheres and PSU-4 silica. c Effect of CTAB concentration in hydrothermal step versus resulting solid surface area.

APTES functionalised materials (Fig. 3a). 40\% APTES-PSU2-G was found to have a $\mathrm{CO}_{2}$ adsorption capacity of ca. $31 \mathrm{mg} \mathrm{CO}_{2} \mathrm{~g}^{-1}$, desorption occurred at temperatures as low as $50^{\circ} \mathrm{C}$. The material with the highest sorption capacity was $40 \%$ APTES-PSU-4-G with a $\mathrm{CO}_{2}$ adsorption capacity of ca. $92 \mathrm{mg} \mathrm{CO}_{2} \mathrm{~g}^{-1}\left(2.09 \mathrm{mmol} \mathrm{g}^{-1}\right)$ which is comparable to several previously reported APTES modified silica materials [13-33]. This corresponds to an amine efficiency

d $\mathrm{N}_{2}$ isotherms, e TGA profiles and $\mathbf{f}$ FTIR for PSU-4 and TEPA and APTES modified PSU-4

of $0.87(\mathrm{~mol} \mathrm{CO} 2 / \mathrm{mol} \mathrm{N})$. The PSU-4 support showed the largest increase in surface area compared with its parent silica before $40 \%$ APTES modification, increasing from $<2$ to $724 \mathrm{~m}^{2} \mathrm{~g}^{-1}$ after pseudo treatment. PSU-4 appears to be the optimal solid support synthesised for APTES modification as the $\mathrm{CO}_{2}$ adsorption capacities of $40 \%$ APTES-PSU-5-G and 40\% APTES-PSU-6-G exhibited significant reductions in performance, with $41.3 \mathrm{mg} \mathrm{CO}_{2} \mathrm{~g}^{-1}$ 
A
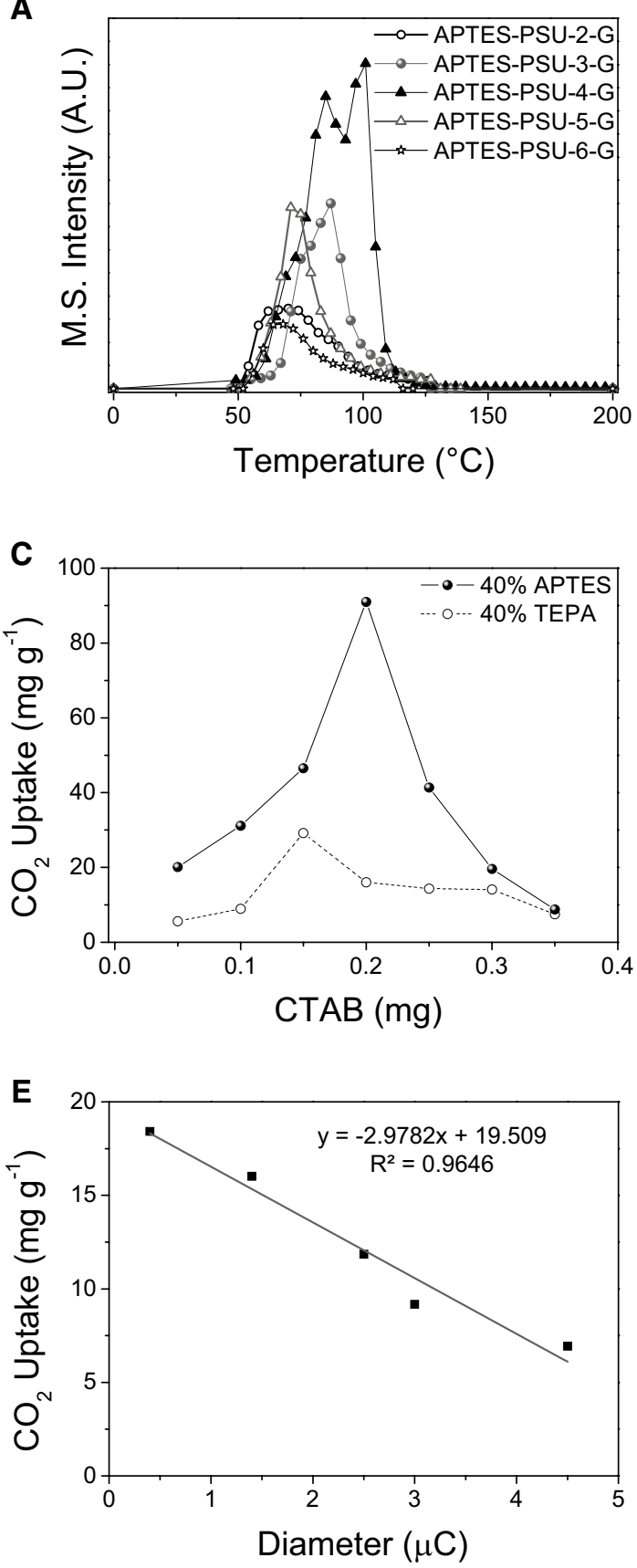

Fig. 3 Temperature programmed desorption (TPD) profiles for a APTES and $\mathbf{b}$ TEPA modified PSU samples. $\mathbf{c} \mathrm{CO}_{2}$ uptake capacities of APTES and TEPA modified PSU samples versus CTAB concentration during synthesis. d Gravimetric $15 \% \mathrm{CO}_{2}$ uptake experiments

and $19.6 \mathrm{mg} \mathrm{CO}_{2} \mathrm{~g}^{-1}$ adsorbed, respectively (Fig. 3c). $\mathrm{CO}_{2}$ gravimetric uptake experiments on $40 \%$ APTES-PSU-4-G (Fig. 3d) were found to be in agreement with TPD experiments and illustrated the fast $\mathrm{CO}_{2}$ sorption kinetics of the amino functionalised PSU-4 material with ca. 90\% saturation occurring in under 5 min exposure to a $15 \% \mathrm{CO}_{2} / 85 \%$ $\mathrm{N}_{2}$ gas mixture.
B
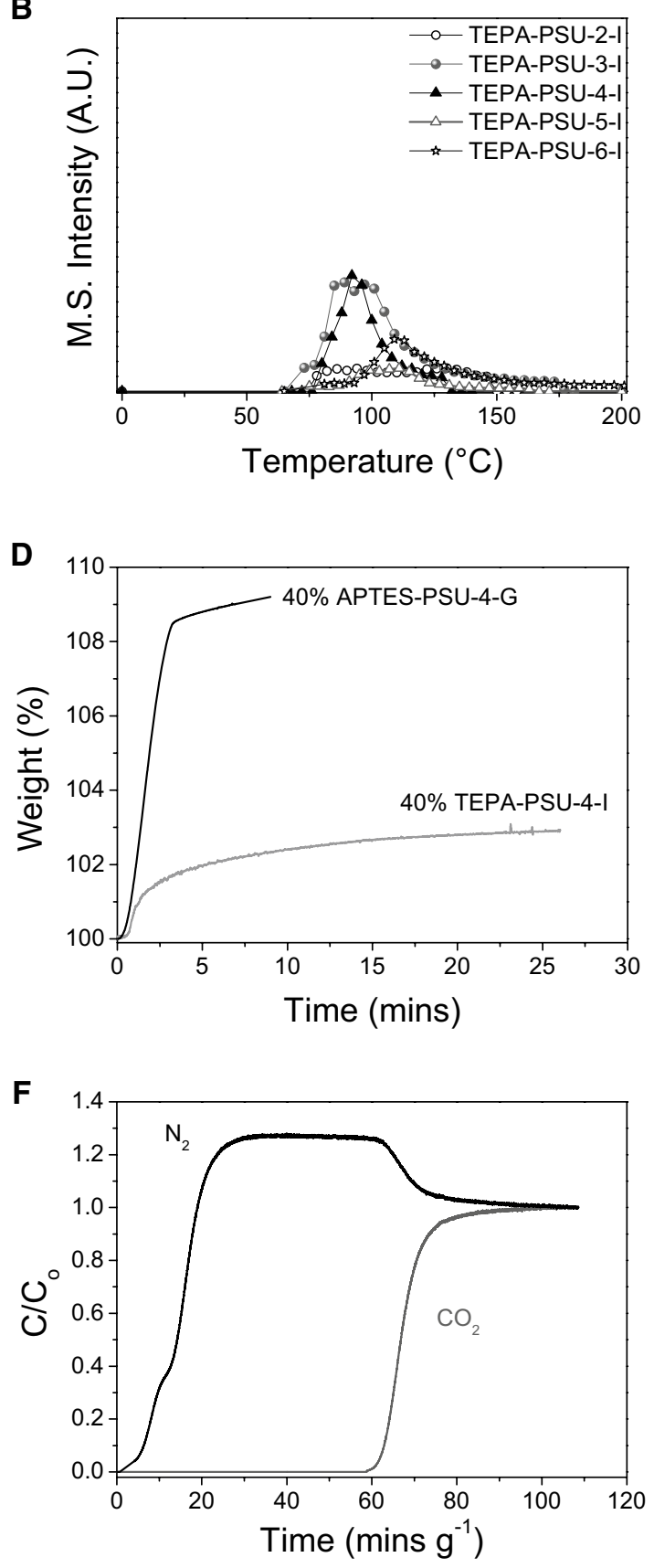

using 40\% TEPA-PSU-4-I and 40\% APTES-PSU-4-G. e $\mathrm{CO}_{2}$ uptake capacities of APTES modified SFB samples versus SFB sphere diameters. f Dynamic gas breakthrough experiments on $40 \%$ APTES-

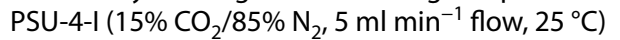

The TEPA modified PSU supports were also found to exhibit significant $\mathrm{CO}_{2}$ sorption (Fig. 3b). $40 \%$ TEPAPSU-2-I was found to have a $\mathrm{CO}_{2}$ adsorption capacity of $8.9 \mathrm{mg} \mathrm{CO}_{2} \mathrm{~g}^{-1}\left(0.2 \mathrm{mmol} \mathrm{g}^{-1}\right)$. This corresponds to an amine efficiency of $0.02\left(\mathrm{~mol} \mathrm{CO}_{2} / \mathrm{mol} \mathrm{N}\right)$. As seen previously, increased support modification with pseudo treatment leads to an increase in the $\mathrm{CO}_{2}$ adsorption capacity 
after surface modification with 40\% TEPA-PSU-3-I adsorbing $29.3 \mathrm{mg} \mathrm{CO}_{2} \mathrm{~g}^{-1}$. This was found to be the most adsorbent material when modified with TEPA. Unlike $40 \%$ APTES-PSU-4-G, 40\% TEPA-PSU-4-I saw a reduction in $\mathrm{CO}_{2}$ adsorption capacity to $16.1 \mathrm{mg} \mathrm{CO} \mathrm{Cg}^{-1}$ adsorbent from the preceding sample. The subsequent samples $40 \%$ TEPAPSU-4-I and 40\% TEPA-PSU-4-I reflect this inverse trend in $\mathrm{CO}_{2}$ adsorption capacity, adsorbing $14.3 \mathrm{mg} \mathrm{CO}_{2} \mathrm{~g}^{-1}$ and $14.1 \mathrm{mg} \mathrm{CO}_{2} \mathrm{~g}^{-1}$ respectively (Fig. $3 \mathrm{C}$ ). In addition to a reduction in $\mathrm{CO}_{2}$ sorption capacity, 40\% TEPA-PSU-4-I was found to exhibit reduced adsorption kinetics during gravimetric $\mathrm{CO}_{2}$ uptake experiments (Fig. $3 \mathrm{~d}$ ), with $90 \%$ saturation occurring in ca. $20 \mathrm{~min}$.

Figure 3e compares the $\mathrm{CO}_{2}$ adsorption capacities of APTES modified SFB silica spheres with various diameters. SFB spheres with diameters ranging between $0.4 \mu \mathrm{m}$ and $4.5 \mu \mathrm{m}$ were modified with APTES using the dry impregnation technique. $\mathrm{CO}_{2}$ adsorption was carried out at $35^{\circ} \mathrm{C}$ for all samples with $\mathrm{CO}_{2}$ desorption occurring below $60^{\circ} \mathrm{C}$. APTES-0.4 $\mu \mathrm{m}$ SFB-I showed the highest adsorption capacity at nearly $18.0 \mathrm{mg} \mathrm{CO}_{2} \mathrm{~g}^{-1}$ adsorbent while APTES-4.5 $\mu \mathrm{m}$ SFB-I adsorbed the least at $7.0 \mathrm{mg} \mathrm{CO}_{2} \mathrm{~g}^{-1}$ adsorbent.

Finally, dynamic gas breakthrough studies were performed on the synthesised material with highest $\mathrm{CO}_{2}$ sorption capacity, 40\% APTES-PSU-4-G (Fig. 3f). Experimental breakthrough studies were conducted for $\mathrm{CO}_{2} / \mathrm{N}_{2}$ $(15 / 85 \mathrm{v} / \mathrm{v})$ mixtures at room temperature. Efficient $\mathrm{CO}_{2} /$ $\mathrm{N}_{2}$ separation was achieved by $40 \%$ APTES-PSU-4-G. $\mathrm{N}_{2}$ gas was eluted through the adsorption bed immediately, whereas $\mathrm{CO}_{2}$ was retained in the adsorbent bed. $40 \%$ APTES-PSU-4-G was found to have a $\mathrm{CO}_{2}$ uptake capacity of ca. $83.6 \mathrm{mg} \mathrm{CO}_{2} \mathrm{~g}^{-1}\left(1.9 \mathrm{mmol} \mathrm{g}^{-1}\right)$. Additionally, $40 \%$ APTES-PSU-4-G was found to exhibit high levels of $\mathrm{CO}_{2}$ removal with an effluent $\mathrm{CO}_{2}$ concentration of $<100 \mathrm{ppm}$ for ca. $55 \mathrm{~min}$. The $\mathrm{CO}_{2}$ breakthrough performance was stable over seven successive cycles (Fig. S10).

\section{Discussion}

SFB spheres were initially synthesised using previously reported methods. Pseudomorphic transformations were found to afford the formation of highly porous silica species. Electron microscopy (Fig. 1) illustrated significant changes in the morphology of the SFB spheres upon exposure to pseudomorphic transformations. Excessive $C T A B$ in the synthesis step was found to negatively affect pseudomorphic silica formation (Fig. 1d). The SFB spheres were found to lose their spherical morphology upon desilication giving way to conjoined silica species upon reassembly. $\mathrm{N}_{2}$ adsorption/desorption experiments illustrated significant changes in porosity of the silica species after pseudomorphic transformations (Fig. 2a). The pseudomorphic silica species exhibit significant increases in $\mathrm{N}_{2}$ adsorption compared to the non-porous SFB silica spheres. This increase in $\mathrm{N}_{2}$ sorption for pseudomorphic species translated to a large increase in surface area $\left(724 \mathrm{~m}^{2} \mathrm{~g}^{-1}\right.$ vs. $\left.<2 \mathrm{~m}^{2} \mathrm{~g}^{-1}\right)$ and pore volume $\left(0.4 \mathrm{~cm}^{3} \mathrm{~g}^{-1}\right.$ vs. $<0.001 \mathrm{~cm}^{3} \mathrm{~g}^{-1}$ ) compared to the SFB spheres. Pseudomorphic species exhibit a typical type IV isotherm which are commonly associated with MCM type mesoporous silica. The pore size distribution for the pseudomorphic species were also found to be consistent with MCM type materials at ca. $3.0 \mathrm{~nm}$. The pseudomorphic transformation method offers a potential method of converting lowgrade silica (i.e. fumed silica) into useful products for multiple applications.

Amino functionalisation was found to be successful on the synthesised materials. PSU-4 was chosen due to its favourable properties in terms of surface area and porosity for modification. Upon post-synthetic modification, $40 \%$ TEPA-PSU-4-I shows a significant reduction in terms of surface area $\left(42 \mathrm{~m}^{2} \mathrm{~g}^{-1}\right)$ compared to that of the parent silica support, PSU-4 $\left(724 \mathrm{~m}^{2} \mathrm{~g}^{-1}\right)$. Similarly, APTES modification gives way to a significant reduction in surface area, with $40 \%$ APTES-PSU-4-G exhibiting a surface area of $12 \mathrm{~m}^{2} \mathrm{~g}^{-1}$. The introduction of functional amines was found to reduce the pore size of the silica materials and in turn made the pore structure inaccessible to $\mathrm{N}_{2}$ during adsorption/desorption testing which in turn led to a significant reduction in surface area. FTIR and TGA studies illustrated that a significant organic content was introduced to the silica support upon post-synthetic modification (Fig. 2e, f). The TEPA functionalised compounds demonstrated weight losses during TGA studies corresponding to the wt\% loading of amine introduced during synthesis. APTES functionalised compounds exhibited significantly less weight loss during TGA studies, this can be attributed to the covalent bond formed between surface $\mathrm{Si}-\mathrm{OH}$ groups and the silanol functional group of APTES. The weight losses observed for APTES functionalised materials can be attributed solely to the decomposition of the propylamine group. The weight loss associated with propylamine decomposition was calculated to be ca. $27 \%$, which suggests an N loading of ca. $4.5 \mathrm{mmol} / \mathrm{g}$ during materials synthesis. Additionally, the amino functionalised materials were found to develop peaks associated with organic species during FTIR analysis. The successful functionalisation of silica species suggested that the resulting materials may be suitable for $\mathrm{CO}_{2}$ gas sorption studies.

Interestingly, when the SFB spheres with varying diameters $(0.4-4.5 \mu \mathrm{m})$ were modified with APTES, the surface area of the silica supports was found to influence the $\mathrm{CO}_{2}$ uptake of the adsorbents (Fig. 3e). Spheres with smaller diameters were found to exhibit higher surface area 
$\left(\mathrm{m}^{2} \mathrm{~g}^{-1}\right)$ and higher $\mathrm{CO}_{2}$ uptakes when amino functionalised while larger spheres exhibited lower surface area and lower $\mathrm{CO}_{2}$ uptake. The relationship between sphere size and $\mathrm{CO}_{2}$ uptake was found to be linear and thus it can be concluded that $\mathrm{CO}_{2}$ uptake of APTES modified materials is dependent upon the surface area of the supporting material. Larger spheres contribute more dead volume during adsorption which in turn leads to lower gravimetric $\mathrm{CO}_{2}$ uptake during adsorption studies. Amino functionalisation of SFB spheres using TEPA was found to be unsuccessful, this may suggest that TEPA functionalisation occurs only within the pore structure of TEPA modified silica supports.

A combination of $\mathrm{CO}_{2}$ gravimetric uptake, TPD and dynamic mixed gas breakthrough studies were performed to analyse the $\mathrm{CO}_{2}$ sorption performance of the amino functionalised compounds. Gravimetric uptake experiments illustrate significant weight changes in amino functionalised materials upon exposure to a $15 \%$ $\mathrm{CO}_{2} / 85 \% \mathrm{~N}_{2}$ gas mixture (Fig. 3a). $\mathrm{CO}_{2}$ sorption occurring in amino functionalised porous materials has been previously shown to occur via a carbamate/bicarbonate chemisorption reaction [10, 45-47]. Gravimetric uptake studies illustrated that the APTES modified material exhibited fast $\mathrm{CO}_{2}$ uptake kinetics while TEPA modified samples exhibited much longer saturation times (Fig. 3a). The slow kinetics of the TEPA modified samples may suggest pore blocking which in turn leads to poor access to $\mathrm{CO}_{2}$ binding sites and longer saturation times. The chemisorption reaction was found to be inherently reversible with initial $\mathrm{CO}_{2}$ desorption occurring at $50^{\circ} \mathrm{C}$ and $60^{\circ} \mathrm{C}$ for APTES and TEPA modified silica's, respectively (Fig. 3c, d). Finally, $40 \%$ APTES-PSU-4-I demonstrated high efficiency for $\mathrm{CO}_{2}$ removal during mixed gas breakthrough studies (Fig. 3f). Highly efficient $\mathrm{CO}_{2}$ removal from simulated flue gas was realised for ca. 55 min with $\mathrm{CO}_{2}$ outlet concentrations of $<100 \mathrm{ppm}$. The $\mathrm{CO}_{2}$ uptake capacity was calculated to be ca. $92 \mathrm{mg} / \mathrm{g}(2.09 \mathrm{mmol} \mathrm{CO} / \mathrm{g})$ which equates to a $\mathrm{CO}_{2} / \mathrm{N}$ efficiency of 0.46 . This performance was maintained over seven consecutive $\mathrm{CO}_{2}$ adsorption/desorption cycles. The pseudomorphic silica samples were found to be highly efficient supports for functional amines and may offer a cheap alternative to highly ordered mesoporous silicas such as MCM-41 and SBA-15 in the future.

\section{Conclusions}

Herein, we have demonstrated an easy way of modifying non-porous silica to form highly porous solids with favourable properties for a number of industrial applications. Nitrogen adsorption/desorption isotherms showed a remarkable surface modification after pseudomorphic treatment, whereas scanning electron microscopy showed that the changes in morphology of solids as the amount of silica directing agent. Pseudomorphic solids were used to obtain a hybrid functional material for $\mathrm{CO}_{2}$ capture by anchoring amine groups onto the resulting silica supports. Highly efficient $\mathrm{CO}_{2}$ sorption performance was achieved by the amine modified pseudomorphic silica species. The results of this study highlight the potential of pseudomorphic silica species for numerous industrial applications and may offer a cheap and versatile alternative to highly ordered porous materials such a SBA-15 and MCM-41.

\section{Supplementary data}

Supplementary material is available free of charge via the Internet at http://www.sciencedirect.com/science/journ al/13858947.

Acknowledgements The authors acknowledge support from the SFIFunded Solar Energy Conversion Strategic Research Cluster (07/SRC/ B1160), the Department of Chemical Sciences, University of Limerick and Glantreo Ltd.

\section{Compliance with ethical standards}

Conflict of interest The authors declare that they have no competing interests.

\section{References}

1. Metz B (2011) Intergovernmental panel on climate change: climate change 2001: Mitigation. Cambridge University Press, Cambridge. ISBN:978-0-521-88011-4

2. Monastersky R (2013) Global carbon dioxide levels near worrisome milestone. Nature 497:13-14. https://doi. org/10.1038/497013a

3. Boot-Handford ME, Abanades JC, Anthony EJ, Blunt MJ, Brandani S, Mac Dowell N, Fernandez JR, Ferrari MC, Gross R, Hallett JP, Haszeldine RS, Heptonstall P, Lyngfelt A, Makuch Z, Mangano E, Porter RTJ, Pourkashanian M, Rochelle GT, Shah N, Yao JG, Fennell PS (2014) Carbon capture and storage update. Energy Environ Sci 7:130-189. https://doi.org/10.1039/c3ee42350f

4. D'Alessandro DM, Smit B, Long JR (2010) Carbon dioxide capture: prospects for new materials. Angew Chem Int Ed 49:60586082. https://doi.org/10.1002/anie.201000431

5. Sumida K, Rogow DL, Mason JA, McDonald TM, Bloch ED, Herm ZR, Bae TH, Long JR (2012) Carbon dioxide capture in metalorganic frameworks. Chem Rev 112:724-781. https://doi. org/10.1021/cr2003272

6. Nugent $P$, Belmabkhout $Y$, Burd SD, Cairns AJ, Luebke R, Forrest K, Pham T, Ma S, Space B, Wojtas L, Eddaoudi M, Zaworotko MJ (2013) Porous materials with optimal adsorption thermodynamics and kinetics for $\mathrm{CO}_{2}$ separation. Nature 495:80-84. https:// doi.org/10.1038/nature11893

7. Mason JA, McDonald TM, Bae TH, Bachman JE, Sumida K, Dutton JJ, Kaye SS, Long JR (2015) Application of a high-throughput analyzer in evaluating solid adsorbents for post-combustion carbon capture via multicomponent adsorption of $\mathrm{CO}_{2}, \mathrm{~N}_{2}$, and 
$\mathrm{H}_{2} \mathrm{O}$. J Am Chem Soc 137:4787-4803. https://doi.org/10.1021/ jacs.5b00838

8. Lu C, Bai H, Wu B, Su F, Hwang JF (2008) Comparative study of $\mathrm{CO}_{2}$ capture by carbon nanotubes, activated carbons, and zeolites. Energy Fuels 22:3050-3056. https://doi.org/10.1021/ef800 0086

9. Kumar A, Madden DG, Lusi M, Chen KJ, Daniels EA, Curtin T, Perry JJ IV, Zaworotko MJ (2015) Direct air capture of $\mathrm{CO}_{2}$ by physisorbent materials. Angew Chem Int Ed 54:14372-14377. https ://doi.org/10.1002/anie.201506952

10. Madden D, Curtin T (2016) Carbon dioxide capture with aminofunctionalised zeolite-beta: a temperature programmed desorption study under dry and humid conditions. Microporous Mesoporous Mater 228:310-317. https://doi.org/10.1016/j. micromeso.2016.03.041

11. Madden DG, Scott HS, Kumar A, Chen KJ, Sanii R, Bajpai A, Lusi M, Curtin T, Perry JJ, Zaworotko MJ (2017) Flue-gas and direct-air capture of $\mathrm{CO}_{2}$ by porous metal-organic materials. Philos Trans A. https://doi.org/10.1098/rsta.2016.0025

12. Kumar A, Hua C, Madden DG, O'Nolan D, Chen KJ, Keane LJ, Perry JJ, Zaworotko MJ (2017) Hybrid ultramicroporous materials (HUMs) with enhanced stability and trace carbon capture performance. Chem Commun 53:5946-5949. https://doi. org/10.1039/C7CC02289A

13. Belmabkhout $Y$, Serna-Guerrero R, Sayari A (2009) Adsorption of $\mathrm{CO}_{2}$-containing gas mixtures over amine-bearing poreexpanded MCM-41 silica: application for gas purification. Ind Eng Chem Res 49:359-365. https://doi.org/10.1021/ie900837t

14. Mello MR, Phanon D, Silveira GQ, Llewellyn PL, Ronconi CM (2011) Amine-modified MCM-41 mesoporous silica for carbon dioxide capture. Microporous Mesoporous Mater 143:174-179. https://doi.org/10.1016/j.micromeso.2011.02.022

15. Serna-Guerrero R, Da'na E, Sayari A (2008) New insights into the interactions of $\mathrm{CO}_{2}$ with amine-functionalized silica. Ind Eng Chem Res 47:9406-9412. https://doi.org/10.1021/ie801186g

16. Heydari-Gorji A, Belmabkhout Y, Sayari A (2011) Polyethylenimine-impregnated mesoporous silica: effect of amine loading and surface alkyl chains on $\mathrm{CO}_{2}$ adsorption. Langmuir 27:1241112416. https://doi.org/10.1021/la202972t

17. Zhang $X$, Zheng $X$, Zhang $S$, Zhao B, Wu W (2012) AM-TEPA impregnated disordered mesoporous silica as $\mathrm{CO}_{2}$ capture adsorbent for balanced adsorption-desorption properties. Ind Eng Chem Res 51(46):15163-15169. https://doi.org/10.1021/ ie300180u

18. Xu X, Song C, Andresen JM, Miller BG, Scaroni AW (2002) Novel polyethylenimine-modified mesoporous molecular sieve of MCM-41 type as high-capacity adsorbent for $\mathrm{CO}_{2}$ capture. Energy Fuels 16:1463-1469. https://doi.org/10.1021/ef020058u

19. Son W-J, Choi J-S, Ahn W-S (2008) Adsorptive removal of carbon dioxide using polyethyleneimine-loaded mesoporous silica materials. Microporous Mesoporous Mater 113:31-40. https:// doi.org/10.1016/j.micromeso.2007.10.049

20. Patil U, Fihri A, Emwas A-H, Polshettiwar V (2012) Silicon oxynitrides of KCC-1, SBA-15 and MCM-41 for $\mathrm{CO}_{2}$ capture with excellent stability and regenerability. Chem Sci 3:2224-2229. https:// doi.org/10.1039/C2SC20356A

21. Kim S, Ida J, Guliants VV, Lin YS (2005) Tailoring pore properties of MCM-48 silica for selective adsorption of $\mathrm{CO}_{2}$. J Phys Chem $B$ 109:6287-6293. https://doi.org/10.1021/jp045634x

22. Huang HY, Yang RT, Chinn D, Munson CL (2002) Amine-grafted MCM-48 and silica xerogel as superior sorbents for acidic gas removal from natural gas. Ind Eng Chem Res 42:2427-2433. https://doi.org/10.1021/ie020440u

23. Chong MAS, Zhao XS (2003) Functionalization of SBA-15 with APTES and characterization of functionalized materials. J Phys Chem B 107:12650-12657. https://doi.org/10.1021/jp035877+
24. Zheng F, Tran DN, Busche BJ, Fryxell GE, Addleman RS, Zemanian TS, Aardahl CL (2005) Ethylenediamine-modified SBA-15 as regenerable $\mathrm{CO}_{2}$ sorbent. Ind Eng Chem Res 44:3099-3105. https://doi.org/10.1021/ie049488t

25. Chang F-Y, Chao K-J, Cheng H-H, Tan C-S (2009) Adsorption of $\mathrm{CO}_{2}$ onto amine-grafted mesoporous silicas. Sep Purif Technol 70:87-95. https://doi.org/10.1016/j.seppur.2009.08.016

26. Sanz R, Calleja G, Arencibia A, Sanz-Pérez ES (2010) $\mathrm{CO}_{2}$ adsorption on branched polyethyleneimine-impregnated mesoporous silica SBA-15. Appl Surf Sci 256:5323-5328. https ://doi.org/10.1016/j.apsusc.2009.12.070

27. Yan X, Zhang L, Zhang Y, Yang G, Yan Z (2011) Amine-modified SBA-15: effect of pore structure on the performance for $\mathrm{CO}_{2}$ capture. Ind Eng Chem Res 50:3220-3226. https://doi. org/10.1021/ie101240d

28. Yue $\mathrm{M}$, Chun $Y$, Cao Y, Dong X, Zhu J (2006) $\mathrm{CO}_{2}$ capture by as-prepared SBA-15 with an occluded organic template. Adv Funct Mater 16:1717-1722. https://doi.org/10.1002/ adfm.200600427

29. Liu X, Zhou L, Fu X, Sun Y, Su W, Zhou Y (2007) Adsorption and regeneration study of the mesoporous adsorbent SBA-15 adapted to the capture/separation of $\mathrm{CO}_{2}$ and $\mathrm{CH}_{4}$. Chem Eng Sci 62:1101-1110. https://doi.org/10.1016/S1872 $-5813(13) 60025-0$

30. Langeroudi EG, Kleitz F, Iliuta MC, Larachi FCA (2009) Grafted amine $/ \mathrm{CO}_{2}$ interactions in (gas-)liquid-solid adsorption/ absorption equilibria. J Phys Chem C 113:21866-21876. https ://doi.org/10.1021/jp908087e

31. Knowles GP, Graham JV, Delaney SW, Chaffee AL (2005) Aminopropyl-functionalized mesoporous silicas as $\mathrm{CO}_{2}$ adsorbents. Fuel Process Technol 86:1435-1448. https://doi.org/10.1016/j. fuproc.2005.01.014

32. Knöfel C, Descarpentries J, Benzaouia A, Zelenák V, Mornet S, Llewellyn PL, Hornebecq V (2007) Functionalised micro-/ mesoporous silica for the adsorption of carbon dioxide. Microporous Mesoporous Mater 99:79-85. https://doi. org/10.1016/j.micromeso.2006.09.018

33. Wei J, Shi J, Pan H, Zhao W, Ye Q, Shi Y (2008) Adsorption of carbon dioxide on organically functionalized SBA- 16 . Microporous Mesoporous Mater 116:394-399. https://doi. org/10.1016/j.micromeso.2008.04.028

34. Maschmeyer T, Rey F, Sankar G, Thomas JM (1995) Heterogeneous catalysts obtained by grafting metallocene complexes onto mesoporous silica. Nature 378:159. https://doi. org/10.1038/378159a0

35. Wang Y, Zhao Q, Han N, Bai L, Li J, Liu J, Che E, Hu L, Zhang Q, Jiang $T$ (2015) Mesoporous silica nanoparticles in drug delivery and biomedical applications. Nanomed Nanotechnol Biol Med 11:313-327. https://doi.org/10.1016/j.nano.2014.09.014

36. Yoo WC, Stein A (2011) Solvent effects on morphologies of mesoporous silica spheres prepared by pseudomorphic transformations. Chem Mater 23:1761-1767. https://doi. org/10.1021/cm102829m

37. Yoo WC, Zhang X, Tsapatsis M, Stein A (2012) Synthesis of mesoporous ZSM-5 zeolites through desilication and reassembly processes. Microporous Mesoporous Mater 149:147157. https://doi.org/10.1016/j.micromeso.2011.08.014

38. Reber MJ, Brühwiler D (2015) Mesoporous hybrid materials by simultaneous pseudomorphic transformation and functionalization of silica microspheres. Part Part Syst Charact 32:243-250. https://doi.org/10.1002/ppsc.201400150

39. Martin T, Galarneau A, Di Renzo F, Fajula F, Plee D (2002) Morphological control of MCM-41 by pseudomorphic synthesis. Angew Chem Int Ed 41:2590-2592. https://doi. org/10.1002/1521-3773(20020715)41:14\%3c2590:AID-ANIE2 $590 \% 3 e 3.0 . C O ; 2-3$ 
40. Stober W, Fink A, Bohn E (1968) Controlled growth of monodisperse silica spheres in micron size range. J Colloid Interface Sci 26:62-69. https://doi.org/10.1016/0021-9797(68)90272-5

41. Nozawa K, Gailhanou H, Raison L, Panizza P, Ushiki H, Sellier E, Delville JP, Delville MH (2004) Smart control of monodisperse Stöber silica particles: effect of reactant addition rate on growth process. Langmuir 21:1516-1523. https://doi.org/10.1021/la048 $569 r$

42. Masalov VM, Sukhinina NS, Kudrenko EA, Emelchenko GA (2011) Mechanism of formation and nanostructure of Stöber silica particles. Nanotechnology 22:275718. https://doi. org/10.1088/0957-4484/22/27/275718

43. Su F, Lu C, Kuo S-C, Zeng W (2010) Adsorption of $\mathrm{CO}_{2}$ on aminefunctionalized Y-TYPE zeolites. Energy Fuels 24:1441-1448. https ://doi.org/10.1021/ef901077k

44. Stevens RW, Siriwardane RV, Logan J (2008) In situ Fourier transform infrared (FTIR) investigation of $\mathrm{CO}_{2}$ adsorption onto zeolite materials. Energy Fuels 22:3070-3079. https://doi.org/10.1021/ ef800209a
45. Zhao A, Samanta A, Sarkar P, Gupta R (2013) Carbon dioxide adsorption on amine-impregnated mesoporous SBA-15 sorbents: experimental and kinetics study. Ind Eng Chem Res 52(19):6480-6491. https://doi.org/10.1021/ie3030533

46. Srikanth CS, Chuang SSC (2012) Spectroscopic investigation into oxidative degradation of silica-supported amine sorbents for $\mathrm{CO}_{2}$ capture. Chemsuschem 5:1435-1442. https://doi. org/10.1002/cssc.201100662

47. Gao F, Zhou J, Bian Z, Jing C, Hu J, Liu H (2013) Dynamic properties in $\mathrm{CO}_{2}$ adsorption on amine-modified MCM-41. Proc Inst Mech Eng E 227:106-116. https://doi.org/10.1177/0954408912 469491

Publisher's Note Springer Nature remains neutral with regard to jurisdictional claims in published maps and institutional affiliations. 